\title{
LOS TRATADOS DEL ARTE DEL VESTIDO EN LA ESPAÑA MODERNA
}

\author{
POR \\ RUTH DE LA PUERTA ESCRIBANO \\ Universidad de Valencia
}

\begin{abstract}
Originated by different proffesions, the need for organization the existing knowledge from the Middle Age produce during the Renaissance the publication of methods of work. Not only were it publicated books about science and art, but it were publicated also about tailoring. The purpouse that it were designed the latter ones was to cut as economically as possible from expensive materials and to stablish standars for styles. The album of un anonymous Milan tailor is the only work wich can be considere to precede Juan de Alcega's Geometria, Practica y Traça. Based on Alcega's book, others were published during the Baroque with the same title Geometria y traças, suposing un step fordward in the teaching and learning the art of tailoring.
\end{abstract}

\section{INTRODUCCIÓN}

La necesidad surgida en el Renacimiento por parte de las distintas profesiones de codificar los saberes existentes y acumulados durante la Edad Media da origen a la publicación de numerosos tratados en diferentes campos, desde la ciencia (geometría ${ }^{1}$, astronomía ${ }^{2}$, ingeniería ${ }^{3}$, etc.) hasta el arte (arquitectura ${ }^{4}$ y pintura ${ }^{5}$ ). Tras el álbum de un sastre anónimo milanés publicado en el siglo xvI, en la sastrería española del Renacimiento y Barroco varios tratados ven la luz con el mismo título Geometría y trazas, creados con la intención de economizar costes

\footnotetext{
1 Para estudiar geometría consúltense los siguientes libros: Los seis primeros libros de Geometría de Euclides (Rodrigo Zamorano. Alonso de Barrera, Sevilla: 1576), Los seis primeros libros de los planos y los onzeno y doceno de los sólidos (Jacobo Kresa. Francisco Foppens, Bruselas: 1689), Tratado de Geometría práctica (Juan Pérez de Moya. Juan Gracián, Alcalá: 1573), Arithmetic demonstrada theorico practica (Corachán. Juan Piferrer, Barcelona: 1719).

2 Muñoz, Jerónimo, Libro del Nuevo Cometa, Valencia. Pedro de Hueste: 1576.

3 Turriano, Juliano, Los veintiún libros de los ingenios y máquinas (edición a cargo de Juan Antonio García-Diego. Facsímil de la Biblioteca Nacional de Madrid. 1997).

${ }^{4}$ En arquitectura, Juan Alberto Ramírez explica los tratados que sobre esta materia se publican en la España Moderna en el libro Los tratados de arquitectra: de Alberti a Ledoux (Barcelona: Hermann Blume, 1988). Entre estos tratados se incluyen Las medidas del romano de Diego de Sagredo (Toledo: Ramón de Petras, 1526), la traducción de los libros de Sebastiano Serlio Regole generali di archittetura por el Maestro arquitecto y rejero Francisco de Villalpando de 1573, Los diez libros de Architectura de Vitrubio por Lázaro de Velasco y Miguel de Urrea, Los diez libros de Architectura de León Baptista Alberto por el alarife Francisco Lozano, Varia conmensuración para la escultura y arquitectura por Juan de Arfe y Sumario y Las estampas del Escorial por Juan de Herrera (1589).

5 Acerca de los tratados de pintura, consúltense los libros De la pintura antigua por Francisco de Holanda (versión castellana de Manuel Denis, Madrid: 1563), De la pintura antigua por Vicente Carducho (Imprenta Real, Madrid: 1865) y Arte de la pintura por Francisco Pacheco (Madrid: Cátedra, 1990).
} 
de producción y al mismo tiempo estandarizar la producción. A los tratados de sastrería publicados en la España Moderna dedicamos nuestra atención en este artículo, junto a los conocimientos científicos de los sastres necesarios para inventar un método de corte, al método de elaboración del traje y a la considerasción intelectual de la sastrería.

\section{LOS TRATADOS DE SASTRERÍA DEL SIGLO XVI}

La publicación de los tratados de sastrería en el siglo Xvi escritos por Juan de Alcega en Álava y Diego de Freyle en Sevilla, se entiende al analizar el contexto científico, revalorizador de la ciencia moderna experimental. Las teorías del monje franciscano y científico inglés Roger Bacon (Bisley 1220-Oxford 1292) con su enfrentamiento al escolasticismo, al defender la ciencia experimental y las de su ulterior homónimo, el que fuera barón de Verulam y canciller de Inglaterra, Francis Bacon (Londres 1516-id. 1626) con su teoría de que la naturaleza sólo se puede conocer observándola, pretendían aplicar la experimentación a los distintos campos del saber. Pero no son ellos, sino los matemáticos y astrónomos, los que de verdad efectúan la revolución, fundando la ciencia moderna experimental. Las teorías de Nicolás Copérnico (Torún 1473-Frauenburg 1543) sobre el desplazamiento de la tierra alrededor del sol describiendo órbitas circulares, las ideas de Johanes Kepler (Wüttemburg 1571-Ratisbona 1630) junto a las observaciones de Tycho Brahe acerca del desplazamiento elíptico de los planetas, constituyen contundentes ejemplos de la aplicación de la observación y experimentación a la ciencia ${ }^{6}$. Trasladando estos avances al campo de la mentalidad del siglo XvI, teóricos como Luis Vives defienden el estudio serio por parte de los hidalgos o estratos medios urbanos ${ }^{7}$ de diversas artes como la sastrería, cocina, construcción, agricultura o navegación, al par que alientan a los científicos a que no desprecien el trabajo manual o artesanal. Incluso dos años más tarde que Luis Vives, Rabelais sugerirá que un príncipe aprenda el método de fabricación de los objetos que utiliza en la vida cotidiana. Es más, se difunde la noción de que los oficios que usan geometría y perspectiva son elevados a una categoría social superior.

\section{El Tratado de Juan de Alcega}

La publicación del primer tratado de sastrería en España tiene como escenario la zona norteña peninsular. Es en la pujante Álava donde este avance técnico se hace posible en el año 1550 y corresponde al hidalgo Juan de Alcega su autoría. Tras varios años de dedicación personal al estudio de esta peculiar ocupación laboral, que no desarrollaría profesionalmente, pero de la que se ocuparía para estar a tono con la mentalidad de la época, que impone el cultivo intelectual y la investigación en aspectos prácticos de determinados oficios, escribe el tratado titulado Libro de Geometría y traça. Lo que no puede saberse con certaza es si Juan de Alcega conoció el libro del sastre milanés o no. Impreso en Madrid en casa de Guillermo Drouy el año 1580 y reeditado exactamente igual en 1589 , el tratado es conocido por notables bibliófilos españoles como Pérez Pastor ${ }^{8}$, Bartolomé Gallardo ${ }^{9}$, el Conde de Navas ${ }^{10}$ y Francisco

\footnotetext{
6 Acerca de los avances científicos consúltense los libros de Isaac Asimoy, Nueva guía de la ciencia, Plaza y Janés, Barcelona: 1996, pp. 14-22 y Carl Sagan, El Cosmos, Barcelona: RBA, 1992, p. 53.

7 Piñero López, José María, Ciencia y técnica en la sociedad española de los siglos xvi y xvII, Barcelona: Labor, 1979, p. 68.

${ }^{8}$ B.N. Pérez Pastor, Bibliografía madrileña, Madrid, Tipografía de los Huérfanos, MDCCCXCI, inv. 015 (460), p. 74.

9 B.N. Bartolomé Gallardo, Ensayo de una Biblioteca de libros raros y curiosos, Madrid: Imprenta de Ribadeneyra, 1863, p. 118, inv. 013-450.

${ }^{10}$ B.N. El Conde de Navas, Revista de Archivos, Bibliotecas y Museos, 3. ápoca, 8, Madrid: 1903, p. 485.
} 

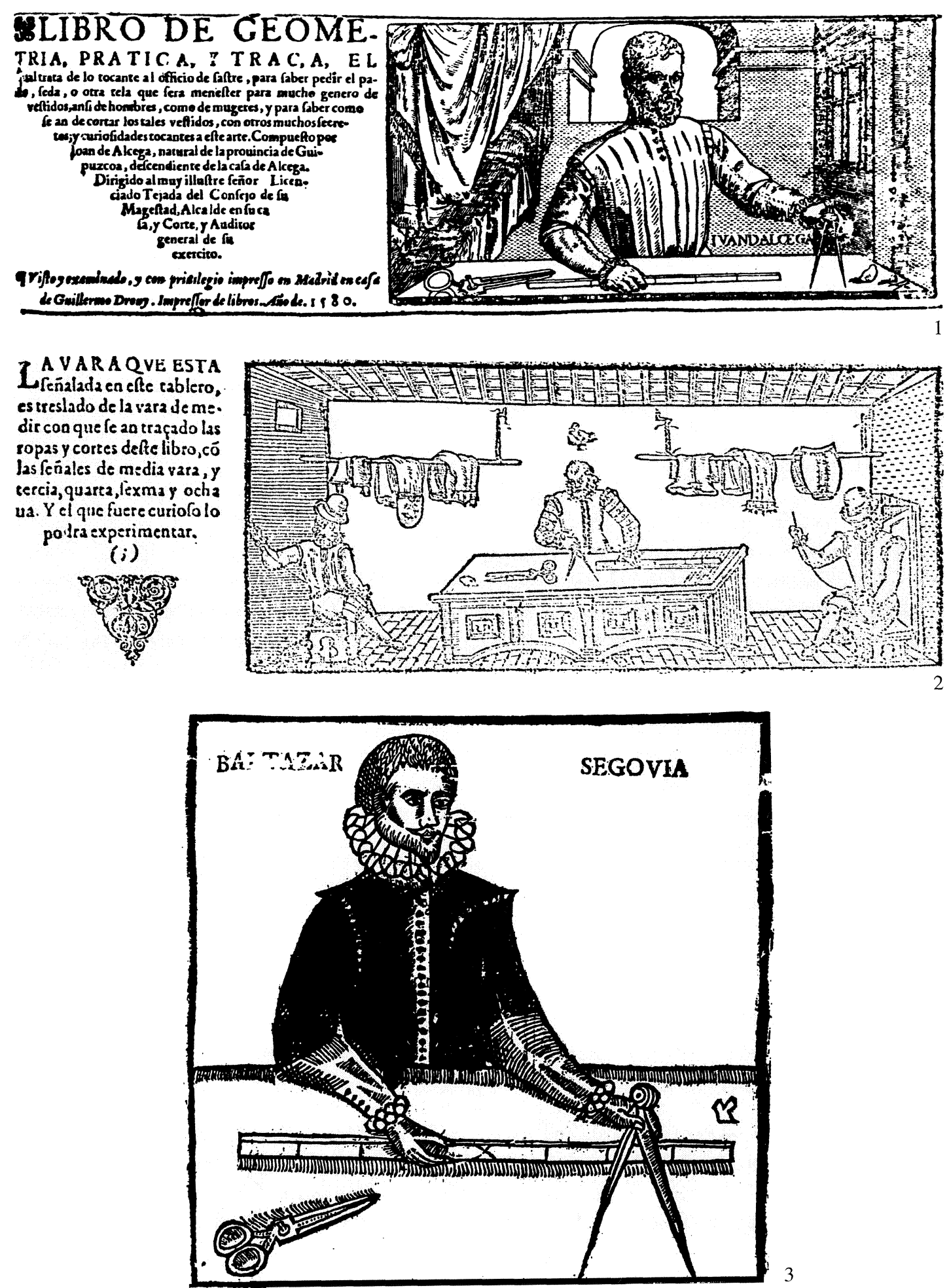

Fig. 1. Grabado de la portada de la primera edición del tratado de sastrería Geometría, Pratica y traça, obra de Juan de Alcega publicada en la imprenta Guillermo Drouy. Madrid: 1580.

Fig. 2. Grabado del tratado de sastrería Geometría y traza realizado por Diego de Freile, publicado por Fernando Díaz. Sevilla: 1588 .

Fig. 3. Grabado del tratado de sastrería Geometría del ofici de sastres publicado por Esteve Libreros en Barcelona: 1617 
Vindel ${ }^{11}$, quienes coinciden en destacar la rareza del libro y reconocer que es el primer tratado publicado en España.

El libro se divide en tres apartados: las cartas, el prólogo y el texto propiamente dicho. Entre las cartas se incluye la correspondiente a la valoración acerca de la calidad del libro por los examinadores Hernán Gutiérrez, sastre de la princesa de Portugal, y Juan López de Burgette, sastre del Duque de Alba. Por ella sabemos que estos sastres poseen un nivel cultural sumamente inferior al del hidalgo Juan de Alcega, ya que no saben ni leer ni escribir, lo cual no les impide reconocer la utilidad del libro tanto para los oficiales y aprendices de sastrería en el ejercicio y práctica de la profesión como para cualquier otra persona que quisiera enterarse de la cantidad de paño o seda requerida para confeccionarse un traje ${ }^{12}$. Si los sastres Hernán Gutiérrez y Juan López de Burguete han sugerido que el objetivo del libro es que los aprendices de sastre mejoren el oficio, la historiografía del siglo xx, por su parte, ha puntualizado que el propósito se encamina más a que los aprendices economicen costos de producción confeccionando trajes en serie con ricas telas ${ }^{13}$.

En el prólogo, Juan de Alcega informa de las dificultades y pleitos que tiene que afrontar con el consejo real para editar el libro, al tiempo que da cuenta de su contenido. Dividido en tres partes, en la primera explica el modo de reducir paños y telas de un tamaño grande a otro más pequeño, basándose en la aritmética. En la segunda da diferentes trazas o patrones de vestidos de hombre y mujer siguiendo las reglas de la geometría y pitipié. En la tercera ofrece una tabla con la anchura de los paños y sedas en uso ${ }^{14}$. Acerca de la declaración del origen de la vara de medir, unidad de medición lineal realizada de hierro o madera perfectamente recta, señala que las hay de distintos largos: grandes, medianas u ordinarias o pequeñas y que se dividen en palmos. Además, informa de su origen: la vara se formó del dedo, espacio que ocupan cuatro granos de trigo puestos de lado y unidos entre sí, medida más pequeña adoptada por los plateros, y luego se originó el pie romano, dieciséis veces el valor de una raya $\mathrm{X}$ y un tercio más pequeña que la vara castellana moderna ${ }^{15}$. Declarado el origen y principio de la vara de medir utilizado en los reinos de Castilla, Juan de Alcega da la medida del ancho de la seda allí elaborada: dos tercios de vara, comparándola con la de los paños finos segovianos o de otras localidades que tienen dos quartos de vara. A continuación, el autor apunta varios problemas con los que, a menudo, se enfrentan los oficiales de sastrería. Uno de ellos es que no saben pedir la cantidad de paño que necesitan a la hora de confeccionar un traje, de suerte que a veces les sobra y otras les falta. Y no saben pedir porque no saben medir. Ciertamente, los sastres miden los paños con lomo (doblados) de una manera diferente a como lo hacen los mercaderes; por consiguiente, suelen encontrarse con menos cantidad de tejido del esperado. Si los sastres midiesen los paños tal y como las pragmáticas sugerían, esto es, siguiendo las tablas, ese error podía evitarse. Al medir determinados géneros como el damasco, J. de Alcega recomienda marcar más cantidad de tejido del necesario por un doble motivo: por un lado, es necesario unir bien las labores o dibujos del damasco y, por otro lado, algunos damascos suelen encoger más de los normal, y por regla general cuando la prenda está terminada queda más corta. Otro problema es que no saben cortar bien el tejido. Con el fin de evitar este error, Juan de Alcega señala cómo deben cortar una prenda en una tela ancha o estrecha y para ello sugiere el uso de números enteros en vez de quebrados. Por ejemplo, un quinto debe ser reducido a un cuarto; un séptimo a un sesto y un noveno a un ochavo.

\footnotetext{
11 B.N. Francisco Vindel, Solaces bibliográficos, Madrid: Instituto Nacional del Libró, 1942, p. 134

12 Alcega, Juan, Geometría, practica y traça, Madrid: Guillermo Drouy, 1589, fol. 2 vº.

13 Bean Ruth, Juan Alcega. Tailor's pattern book, 1589. (Facsímile. Carlton, Bedford: 1981), p. 10.

14 Alcega, Juan, op. cit., fol. $3 \mathrm{v}^{\circ}$.

15 Alcega, Juan, op. cit., fol. Y A.
} 
El sistema de representación gráfico empleado por J. de Alcega para la realización de patrones es el siguiente: delante de la cruz que acompaña al nombre de la prenda señala el número de varas de tejido que hace falta y la anchura del mismo. Una vara se indica con una $b$, dos varas con dos b $(b b)$; si delante de una $\mathrm{b}$ aparece entre paréntesis la letra $o$, denota una ochava, y si aparece una $s$, es una sesma. Cada pieza del patrón grande se define por una línea continua «— $\longrightarrow$ que indica por dónde se debe cortar el tejido con tijeras, mientras que cada pieza menuda o añadida denominada respectivamente cuchillo y cama se señala con una línea de puntos intermitentes «-------------». Dentro de las líneas se escriben unas letras mayúsculas que se repiten en otras piezas del patrón para informar de que esas piezas deben situarse juntas ${ }^{16}$.

Tras la declaración de la vara de medir, Juan de Alcega presenta patrones de trajes: jubones de hombre y mujer de seda, diferentes modelos de capas solas o a juego con sayos y ropillas, mantos, herreruelo con ropilla, ropillas, ropas, sayos, monjiles y banderas de guerra.

\section{El Tratado de Diego de Freyle}

El libro Geometría y traça para el Oficio de los Sastres es obra de Diego de Freyle, natural de la ciudad de Granada y vecino de la ciudad de Sevilla. En Sevilla se examina del oficio, con lo que nos quiere decir que allí se convierte en Maestro de sastre y en Sevilla se publica su libro en la imprenta de Fernández Díaz el año 1583. El autor es mencionado por Campomanes en su Apéndice a la Educación popular del siglo XVIII ${ }^{17}$.

Dirigido a Don Juan Hurtado de Mendoza, Rojas y Guzmán, conde de Orgaz, prestamero mayor de Vizcaya, señor de la casa de Mendoza y asistente de Sevilla y de su tierra, el libro se divide en cinco partes: sonetos, cartas, prólogo, problemas técnicos y las traças. Los sonetos son compuestos por Miguel Díaz de Alarcón, quien los dedica a Diego de Freyle. En los dos primeros cuartetos del primer soneto, el autor alaba a los inventores de cualquier tipo de Arte u oficio, mientras que en los tercetos, tras recordar a Euclides por ser el inventor de la geometría como ciencia, elogia a Freyle por saber trazar (dibujar) mediante geometría como hacen los buenos sastres. En los dos primeros cuartetos del segundo soneto, tras remitir a las ideas de Séneca (Córdoba c. 3 a.J.C.-Roma 65 d.J.C.) propugnadas en contra de la pereza y a favor del estudio, el autor considera a Freyle un verdadero artista, un Maestro de su ocupación laboral: la sastrería, a la que considera un Arte. En conclusión, en ambos sonetos M. Díaz de Alarcón mira la Antigüedad para justificar el uso por Freyle de la geometría euclidiana y su dedicación al estudio propuesto por Séneca. Veamos el poema de Alarcón:

«A los que officio y arte an inventado

Es justo que a su induftria agradezcamos

Las cofas milagrofas que gozamos

Que con divino ingenio han procurado.

$Y$ aunque es verdad que haverlos començado

Su origen y principio les devemos

A los que hallan como los fepamos

Devemos mas, pues lo an facilitado

\footnotetext{
${ }^{16}$ Alcega, Juan, op. cit., fol. B 4.

${ }_{17}$ Campomanes citado por Julián Marías en La España posible en tiempos de Carlos III, Madrid: Sociedad de estudios y publicaciones, 1963, p. 82.
} 


\section{GEOMETR I A Y T R A C, A P A R A E L O I CIO DE LOS SASTRES, PARA QVE SEPAN COMO AN DE CORTAR QVALESQV́IER generos de ropas, afsi de Seda, como de paño, Tela de oro y de Plata, Lanilla, y Rajeta batanada, y èe otra qualquier tela a afsi para hombres, como para mugeres, Clerigos y frayles. Compuelto y traçado por Diego el Frey'e nasural de !a civdad de Granada, y vezino de la ciudad de Seuilla, examinado del dicho ofticio . \\ Dirigido a Donluan Hurrado de Mendoça, Rojas y Guzmzn Conde de Orgaz, Prefamero majoz de Vizcayz, Señor de la cała de Mendo Ģa, y Afsiftente de Seuilla y fu tietrra. \\ EN SEVILLA. \\ . 38 .}

L LIBRE DE GEO METRIA

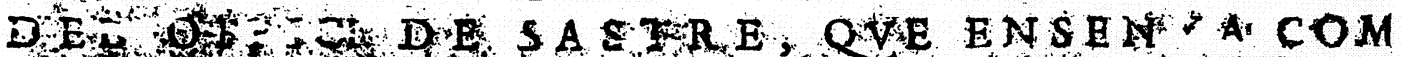

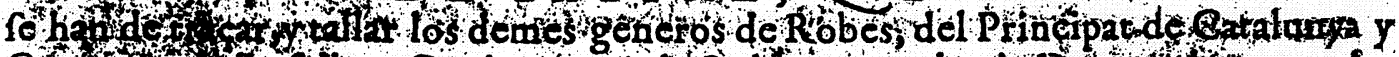

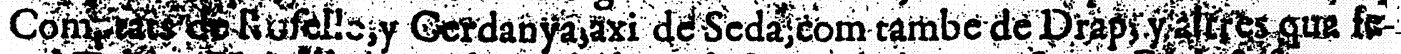

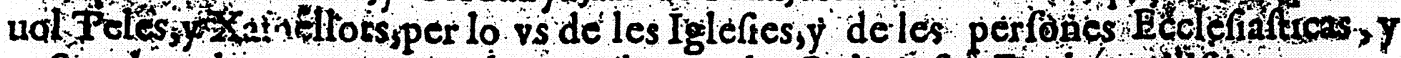

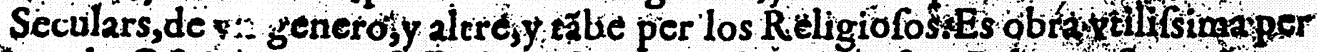

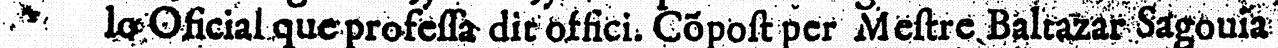
Saftre en la fídelifsima Vila de Perpinýa:

DIRIGIT A NOSTRASENTORA DEL MONT DEL CAR AE

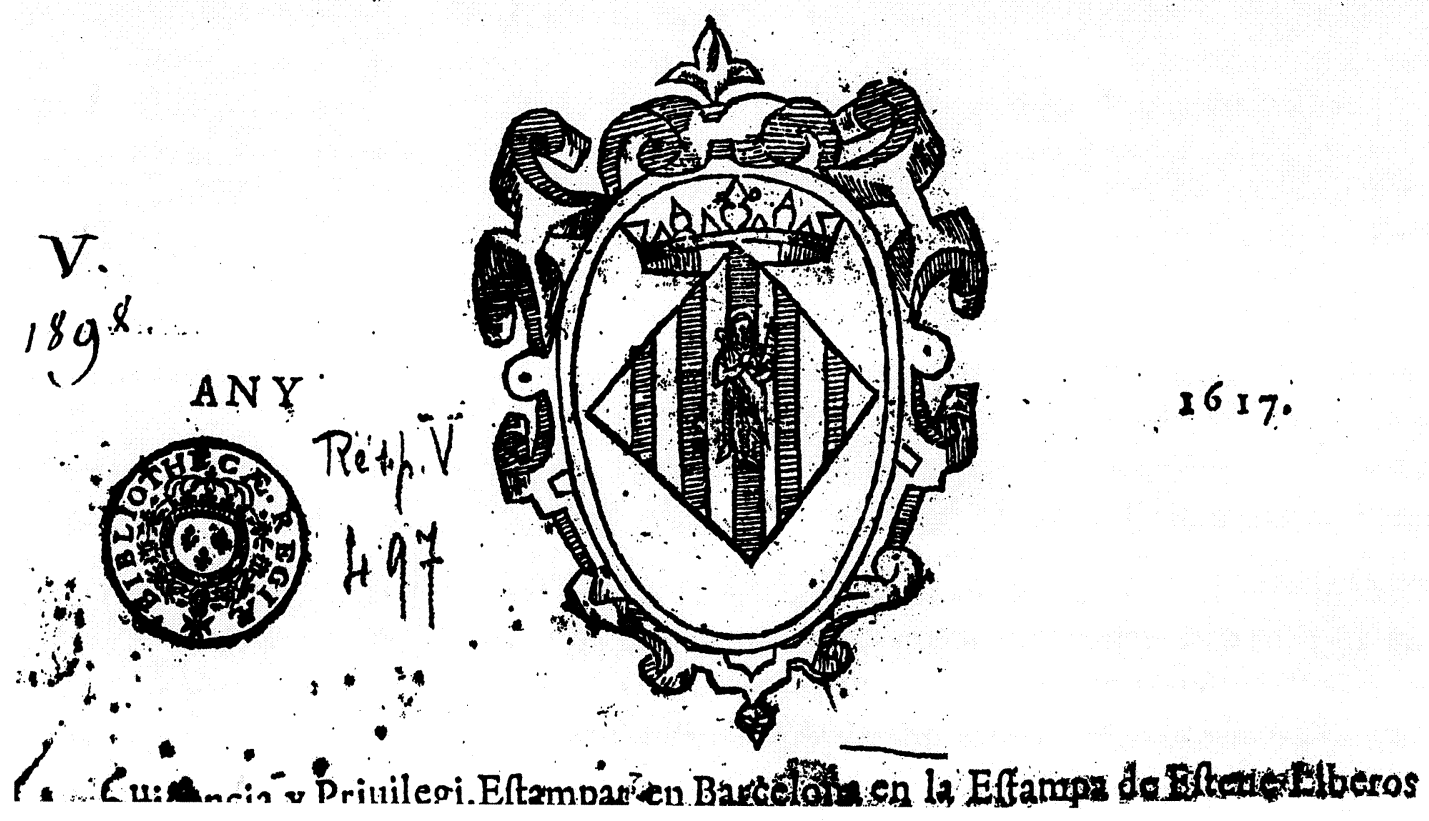

Fig. 4. Portada del tratado de sastrería Geometría y traza realizado por Diego de Freyle, publicado por Fernando Díaz en Sevilla: 1588

Fig. 5. Portada del tratado de sastrería Geometria del ofici de sastres escrito por Baltasar Segovia, publicado por Esteve Libreros en Barcelona: 1617 


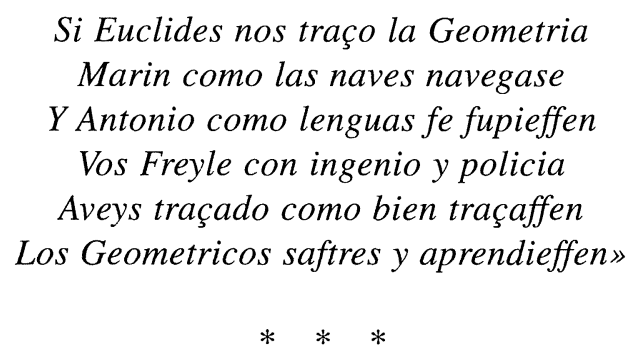

«Dize Seneca ser verguença eftraña

Que pierde el ombre por tener pereza cofas devidas a naturaleza

Que es don faberlas de inmortal hazaña

Que la negligencia culpa y daña y el eftudio da fe, valor y grandeza, Bien digna es al que eftudia la nobleza Si es adquirida por fu eftudio y maña

Y como la razon efto conoce $Y$ a la ciencia fe deve paga inmenfa El nombre de Maestros les concede

Y fi fe lo da por premio y recompenfa

Cosa es bien digna que tal nombre goze Freyle pues fer maeftro en fu arte puede» ${ }^{18}$.

En la carta que Diego de Freyle dirige al conde de Orgaz le explica la importancia de este libro no sólo para los oficiales de sastre sino también para todos aquellos que no deseen ser estafados cuando compran tejidos o quieran saber si se les confeccionan trajes de buena o mala calidad ${ }^{19}$ :

El 1 de junio de 1588 los alcaldes y veedores sevillanos, Diego de Pereyra de Castro y Diego Rodríguez, certifican haber visto, por mandato del conde de Orgaz, el libro de Diego de Freyle, del cual reconocen su utilidad. En el prólogo que el autor dirige a los lectores, menciona la importancia del oficio, manifestada en el gran número de personas dedicadas al mismo, pero alude también a la falta de Maestros de sastre dedicados a la elaboración de un tratado. Excepto el vizcaíno Juan de Alcega, no menciona a ningún otro sastre que hubiese inventado un método de corte, y sus trazas ya se habían pasado de moda, lo que justifica, en opinión de D. de Freyle, la necesidad de elaboración de un nuevo tratado que contenga los cortes esenciales, que son casi siempre los mismos, aunque el tiempo los haya alterado ${ }^{20}$ :

En el apartado titulado traças y cortes del Oficio el autor habla de la existencia de diferentes varas usadas en España (Portugal, Castilla, Andalucía, Extremadura y Valencia), las cuales fueron creadas por Alfonso VI (1040-Toledo 1109) en las Cortes de Toledo en la esperanza de que los mercaderes se entendiesen mejor, y después explica la necesidad por parte de un buen

${ }^{18}$ Folger Shakespeare Library. Freyle, Diego de, Geometría y trazas para el Oficio de sastre, Sevilla, Imprenta Fernando Díaz, 1588. Sig.: TT 575 F 8 cage. Fol. A 3.

19 Freyle, Diego de, Carta a Diego Hurtado de Mendoza, op. cit., fol. A 3.

${ }^{20}$ Freyle, Diego de, prólogo, op. cit., fol. 1. 
oficial de saber cuántas varas caben en una pieza de tela para poder cortar telas pequeñas de otras más grandes. Además, el autor recomienda a los Maestros que no mientan a los oficiales ni les encomienden demasiados pedidos porque ello va en detrimento de la calidad del producto terminado, ya que el cliente o parroquiano ${ }^{21}$ que no quedaba satisfecho a menudo dejaba de pagar al sastre, criticándolo y cambiando de tienda ${ }^{22}$. Respecto a determinados problemas mencionados por el autor, se refieren tanto a las posturas y gestos que deben adoptar los oficiales en el lugar de trabajo como a la parte técnica de la elaboración de trajes. La manera más sencilla de afrontar la primera cuestión consiste en sentarse sobre una banqueta de media vara de alto con la espalda recta, colocar la ropa sobre la rodilla derecha, no montar las piernas una sobre otra sino simplemente juntar la punta del pie derecho sobre el izquierdo o sentarse a lo indio, empujar la aguja con la mano derecha hacia afuera para evitar picarse la nariz y el carrillo derecho, no sacar la lengua cuando están cortando con las tijeras, no hablar demasiado sino permanecer callados, ya que numerosos oficiales se dedican a contar cuentos, lo que descuida la calidad de la prenda, y no cantar, excepto cuando se hallen solos velando por la noche, dado que en las casas de los Maestros hay mujeres e hijas que no deben escuchar cantos deshonestos. En realidad, de esta última costumbre tan sólo quedaban los ecos, pues ya no se solía cantar en tiendas de sastres afamadas por ser típico de cardadores, tundidores o peraires. En relación al segundo punto, el de los problemas técnicos, el autor da consejos sobre cómo cortar varias prendas. Por ejemplo, para cortar una capa recomienda doblarla a lo largo, meter media vara por una orilla y no rasgarla. Para cortar seda, D. de Freyle recomienda a los sastres que pregunten al mercader qué tipo de caída tiene el tejido, cuánto mide de ancho, cuánto necesita y qué número de cenefas caben en la pieza. Sobre la reducción del paño, D. de Freyle indica la equivalencia entre los paños y las sedas de modo que la proporción en número de varas de tejido de seda con respecto a la de paño es la siguiente: 3 a 1,6 a 2,9 a 3, 12 a 4,15 a 5,18 a 6,21 a 7 , etc. En otras palabras, tres varas de seda de dos tercios de ancho equivalen a una vara de paño de dos varas de ancho; seis varas de seda equivalen a dos varas de paño de dos varas de ancho, y así sucesivamente ${ }^{23}$. Esta última indicación debería resultar muy útil a los sastres con objeto de que éstos tuviesen siempre en cuenta la tendencia de la seda a encoger y, por tanto, comprasen más cantidad de tejido y pensasen en la cantidad de seda que equivale al paño.

Dado que Diego de Freyle no ordena las traças que presenta en el libro, nosotros vamos a ordenarlas alfabéticamente, resultando ser banderas de guerra, balandranes, bohemios, calzones, conjuntos de capa y sayo españoles y florentinos, otros iguales para letrado o para hombre anciano, cotaneras o mongiles trenzados, ferreruelos, manteguelos, mantos, mucetas, marlotas, ropas, ropillas, sayas, sayos, sobrerropas, sotanas, túnicas, vaqueros y vestidos enteros compuestos de ferreruelo, ropilla y calzón de paño estrecho.

\section{Los tratados del siglo XVII}

Pocos siglos son tan elocuentemente ricos en pintura y literatura como el xviI, de ahí que hoy lo llamemos siglo de oro. En efecto, varios tratados ven la luz. El tratado de Geometría y traças de Baltasar Segovia es publicado en Barcelona el año 1617, único dedicado mayormente a indumentaria religiosa y que incorpora patrones de tiendas de campaña. El tratado de Geometría y traças de Francisco de la Rocha es publicado por Patricio Mey en Valencia el año

\footnotetext{
${ }^{21}$ Parroquiano es la persona que acostumbra a comprar en una misma tienda lo que necesita, o servirse siempre de un artesano, oficial, etc. Véase: Diccionario de la Real Academia de la Lengua, Madrid: Espasa Calpe, 1970, p. 981.

${ }_{22}$ Freyle, Diego de, op. cit., fol. sin numerar.

23. Ibídem, fol. C 1-C 4 .
} 

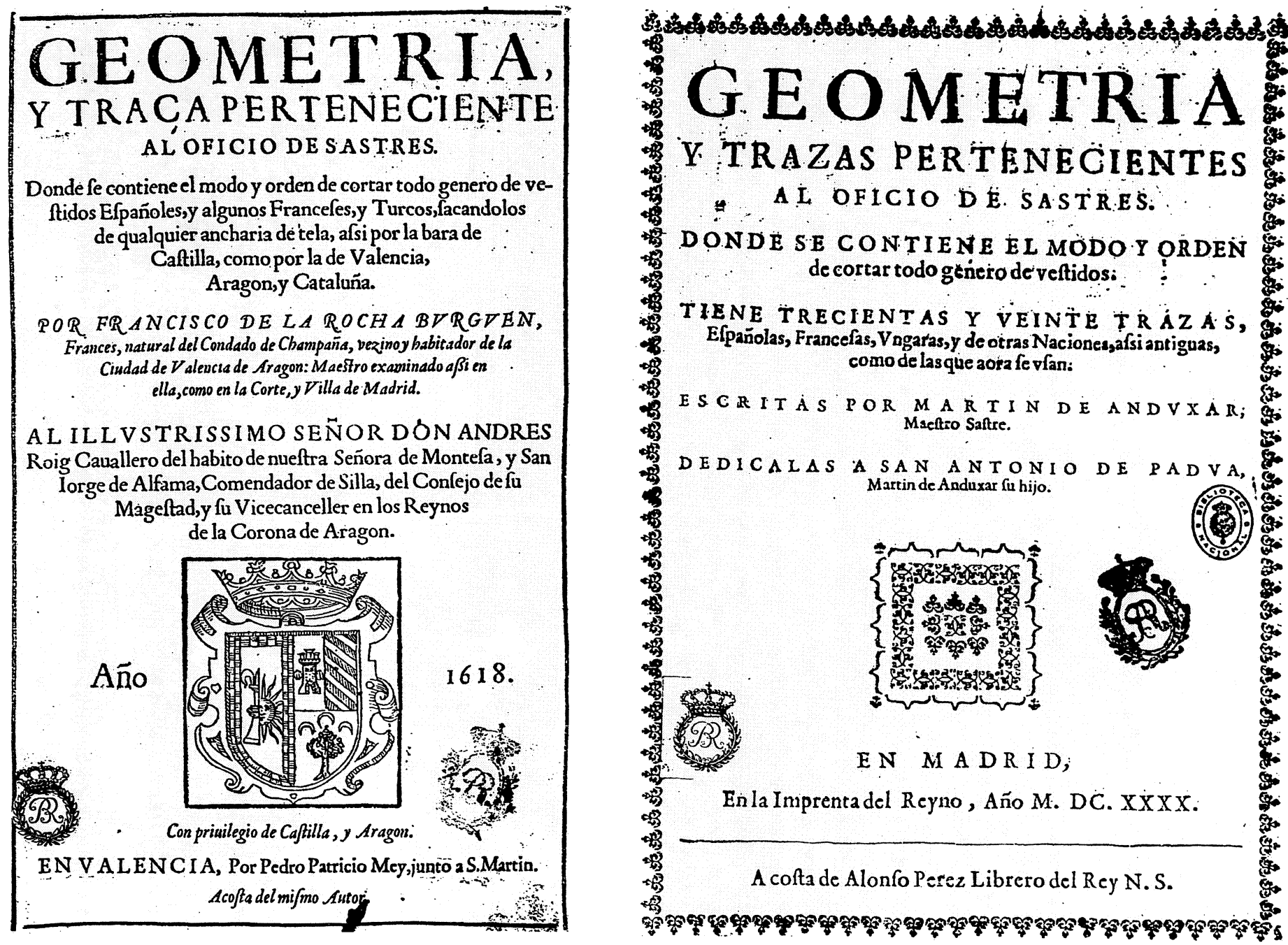

Fig. 6. Portada del tratado de sastrería Geometria y traça ejecutado por el sastre francés afincado en Valencia Francisco de la Rocha, publicado por Patricio Mey en Valencia: 1618 Fig. 7. Portada del tratado de sastrería Geometria y trazas llevado a cabo por Martín de Andújar, publicado por la Imprenta Real en Madrid: 1640. 
1618; el tratado de Geometría y traças de Martín de Andújar es publicado por la imprenta Real en Madrid en 1640, setenta y cuatro después de que la Corte se trasladara allí. Veámoslos:

\section{El Tratado de Baltasar Segovia}

El libro Llibre de Geometría del ofici de sastres donde se han de traçar y tallar los demes géneros de Tobes, del Principat de Catalunya y Comptats de Rofello y Cerdenya, es una obra de Baltasar Segovia, sastre oriundo de la villa de Perpiñán, que compone en dicha localidad ${ }^{24}$, pero que escribe en lengua catalana por ser en Barcelona donde ejercería el oficio. Impresa por la Compañía de Jesús en la estampa de Esteve Libreros de Barcelona el año 1617, la obra sale a la luz un año antes que la de F. de la Rocha (1618). Dedicada a la Virgen del Carmen, el autor la dirige a los oficiales de sastrería, como indica en la portada.

El autor divide el tratado en nueve parte que corresponden a los siguientes apartados: $1{ }^{\text {a: }}$ : licencia concedida por el Obispo de Barcelona el 16 de febrero de 1617 para poder vender el libro por tiempo indefinido; $2 .^{\text {a }}$ : grabado de la Virgen del Carmen de factura mediocre; 3 . $^{\text {a }}$ tabla de las traças, con destino a personas civiles y eclesiásticas del principado de Cataluña, Roselló y Cerdeña. Como peculiaridad de este tratado y a excepción del libro del sastre milanés, es el único que incorpora dos patrones de tienda de campaña, uno para capitán de infantería y otro para capitán simple. Los trajes representados son hábitos, bohemios, casullas, capotes, capas, camisas, cotas, cogullas, dalmáticas, faldillas, gabanes, gramallas, jubones, gregüescos, medias lobas, mantos, monjiles, pontificales de Obispo, paramentos de justas reales, ropas de levantar, ropas normales, sotanas, sayas, sayos vaqueros, togas, tiendas de campaña, vestidos. Con todo, hemos de advertir que el microfilm del tratado que no han enviado desde la Biblioteca Nacional de París contiene los dibujos de los patrones superpuestos, de modo que resulta imposible poder descifrarlos. 4. ${ }^{\text {a: }}$ Nota de las erratas acompañada de la declaración de las letras y cifras de las figuras del libro para mayor claridad del oficial; 5. a: carta del autor de la Virgen del Carmen dedicándole el libro; 6. ${ }^{\mathrm{a}}$ : grabado representando a Baltasar Segovia con la vara, tijeras y compás; 7.a: prólogo donde señala la utilidad del libro para los aprendices; 8.a: el verso siguiente: «Baltasar no per mont vot/ aveu de fer alabat/ puix dira que no me ha obligat/lo ferme compatriot./Voftra fubtilefa en tot/ difposada ab Geometria/ fervint de eftrado à Maria/ reb della tal refplandor/ que la enveja tindra por/ a la flaca mufa mia,/ Obra tan ben acabada/ als Saftres fera un mirall/ per aforrar de treball/ a la tifora afilada,/ y fi alguna defllenguada/ voldra paffar mes avant/fora de compas tallant/ teniu per certa fenyal/ que tant una obra mes val/ quant mes la van menyfpreant»; $9 .^{\circ}$ explicación del sistema de patronaje basado en las cañas o varas y presentación de las trazas. Explica el sistema de patronaje del modo siguiente. Delante de la letra C (denota la caña o vara, medida usada en Cataluña equivalente a la vara castellana, la cual mide medio palmo) o la letra $\mathrm{P}$ (denota el palmo) se marca el número de cañas requeridas. Y cuando el número dos va sobre el cuatro significa dos cuartos de caña, cuando el tres va sobre el cuatro denota tres cuartos de caña...

\section{El Tratado de Francisco de la Rocha}

El libro titulado Tratado de Geometría y traça, publicado por Patricio Mey en Valencia en 1618, es una obra de Francisco de la Rocha, sastre francés natural del Condado de Champag-

${ }^{24}$ B.N.P., Segovia, Baltasar, Geometria del ofici de sastres, Barcelona: Esteve Libreros, 1917. 
ne, criado en Valencia que, a la edad de cincuenta y dos años, se examina en la Corte y Villa de Madrid a fin de poder ejercer el oficio de la sastrería en España. Llega a ocupar el cargo de Clavario del Gremio de sastres de Valencia, donde tiene que solventar numerosos problemas internos, como el intento de separación de algunos oficiales que no están de acuerdo con los capítulos por los que se rige dicho Gremio ${ }^{25}$. Famoso en su época, el autor es mencionado por bibliófilos madrileños de la talla de Nicolás Antonio, quien lo define como un operario mecánico geométrico: infcriptus auctor legitus operis mechanico-geometrici huytis ${ }^{26}$.

El autor divide el libro en tres partes: a las cartas de aprobación y la declaración acerca de la vara de medir, le sigue la explicación de los problemas técnicos de oficiales de sastre y las soluciones; finalmente procede a la presentación de los patrones. Entre las cartas se incluye el privilegio real de 11 de marzo de 1615 por el que se concede licencia a Francisco de la Rocha para poder imprimir y vender el libro durante diez años, el mismo período que J. de Alcega. En caso de fraude, es decir, de que alguna persona vendiese el libro sin permiso de su autor, sería multado con quinientos florines que se repartirían en tres partes: una para el autor y las restantes para el Rey y el Gobernador de Valencia. Si el defraudador fuera impresor, perdería los moldes de los libros que hubiese impreso. Como medida proteccionista y con el fin de asegurar el uso de libros nacionales, no se permitía la entrada de libros extranjeros similares en aquellos lugares donde se estuviese vendiendo el de F. de la Rocha ${ }^{27}$. Siguiendo la tónica general europea del mecenazgo dispendiado por la nobleza a artistas y escritores, Andrés Roig, caballero de la orden de Montesa, debió ayudar a F. de la Rocha a publicar el libro, lo que se explica por la carta de agradecimiento que el sastre incorpora, dedicándole afectuosamente su obra ${ }^{28}$. En la carta dirigida al lector y tras señalar la importancia y antigüedad del oficio de sastre, F. de la Rocha expresa su objetivo de completar el tratado del vizcaíno Juan de Alcega, al tiempo que narra los avatares por los que tiene que pasar para poder publicar su obra. Llega a la Corte y suplica a los señores del Consejo Real de Castilla y Aragón le den el privilegio; sin embargo, ellos, aun destacando la utilidad del libro para el oficio de la sastrería, le señalan que debe ser examinado previamente en la Corte, pues al ser extranjero dudan de que sea el verdadero autor de la obra. Frente a lo que ocurre normalmente, todos los veedores de la Corte acuden a examinarle y cada uno de ellos le pide que realice diferentes traças (dibujos de trajes) y cortes de vestidos del libro. Finalizado el examen, se le concede el título de Maestro de la Corte y villa de Madrid. El autor agradece especialmente el apoyo prestado durante toda la jornada del examen de la Corte a los examinadores de la Reina, Pedro González y Francisco de Soria junto al sastre Mateo Puello, el jubetero Alonso Pérez y demás veedores, quienes le encuentran hábil y suficiente para confeccionar trajes, banderas de guerra y estandartes reales ${ }^{30}$. En la carta del examen de la villa de Madrid de 25 de febrero de 1615 se le reconoce el título y, por tanto, facultad para abrir una tienda y contratar aprendices y oficiales tanto en la Corte como en el resto de las ciudades, villas, lugares y señoríos particulares de España. También en ella se solicita al virrey, al capitán general, a los jurados y

${ }^{25}$ B.N. Respuesta de Francisco de la Rocha Burguen a los oficiales del Gremio de sastres de Valencia, sin fecha de edición, Sala Cervantes, sig. VE 209/74. Los oficiales se oponían a los capítulos por cuestiones económicas principalmente. Se proclamaban en contra de la elevación de la tacha o impuesto anual en metálico que, impuesta por Francisco de la Rocha, debía cubrir los gastos del pleito contra los calceters y el mantenimiento del altar del Monasterio de San Vicente de la Roqueta. Además, los oficiales exigían ser informados del estado de las cuentas gremiales.

${ }^{26}$ B.N. Nicolás Antonio, Biblioteca Hispano Nova, Tomo I, p. 467, sig. R bis 5-2 013 (46). Véase también: De la Puerta, Ruth, Historia del Gremio de sastres y modistas de Valencia, Valencia, Ayuntamiento, 1997, p. 184.

${ }_{27}$ B.N. Francisco de la Rocha, Geometria y traças, Patricio Mey, 1618, Sala Cervantes, sig. R 2502, privilegio y licencia de Aragón, fol. s 3.

${ }^{28}$ Francisco de la Rocha, Carta al ilustrísimo señor Don Andrés Roig, op. cit., fol. s 4.

${ }^{29}$ Francisco de la Rocha, Carta dirigida al lector, op. cit., fol. 5.

${ }^{30}$ Francisco de la Rocha, Carta de examen de la corte, op. cit., sin numerar. 
demás gobernadores del reino de Valencia que permitan a F. de la Rocha ejercer libremente en Valencia el oficio de sastre ${ }^{31}$.

En otra carta F. de la Rocha presenta una declaración de la vara de medir, tomada de la mano del hombre, dividida en cuatro palmos, que a su vez se subdividen en números quebrados: tercios y sextos. Respecto a los problemas técnicos, F. de la Rocha recomienda a los oficiales el uso de una vara de determinado tamaño y al mismo tiempo la utilización de un tejido cuyo largo tenga un número concreto de varas. Por ejemplo, para confeccionar una vasquiña de mujer de estatura media que requiriera una tela de largo de dos varas de Castilla menos un sexto, propone utilizar una tela de vara y media de largo más dieciséis palmos de ruedo. Asimismo señala que muchos sastres podían llevar trabajando toda su vida, pero no eran capaces de determinar la cantidad de tejido que debían usar, es decir, cuánto debían destinar para el ruedo de una falda, cuánto para el largo, etc. De hecho, a F. de la Rocha solían preguntarle otros sastres qué cantidad de tejido requería un hombre alto, a lo cual les contestaba que lo que primero debían hacer era tomar la medida del largo al cliente, después pasarla a una tela de dos varas menos un sexto de largo y a continuación había que ver cuántas varas ordinarias cabían dentro de esa vara más larga. Al tomar medidas al cliente, el autor recomienda a los sastres que se fijen en que el cliente no lleve los chapines puestos y que se fíen de las medidas tomadas inicialmente y no las cambien, cual solía acontecer. Tras la toma de medidas, estipula el modo de medir el paño correctamente: sobre el tablero y con la vara, pues tanto en Madrid como en Valencia los sastres solían medir el paño en el aire, de suerte que en numerosas ocasiones se encontraban con media cuarta menos. Por otra parte, F. de la Rocha especifica la obligada necesidad de cortar el tejido después de haber sido abatanado o mojado, ya que en Valencia los sastres tenían la mala costumbre de cortar el paño antes de ser tundido, abatanado o mojado, lo cual producía un error irrecuperable: el encogimiento del tejido. Finalmente, establece el significado de las señales indicadas para reconocer la pieza del traje. Al igual que J. de Alcega, unas letras indican la cantidad de tejido usado en los distintos moldes o piezas y por medio de puntitos encima de las letras se indican las piezas que no están enteras, que se denominan camas, cuchillos o recuchillos ${ }^{32}$.

A diferencia de Juan de Alcega, los patrones de los que el autor ofrece dibujo aparecen ordenados alfabéticamente. Corresponden a indumentaria tanto civil como religiosa de hombre y mujer, adultos y niños. Son las que a continuación exponemos: aderezo de seda de caballo para justas reales y justas ordinarias, albornoces, almáticas, balandranes, banderas de guerra, bohemios, calzones, conjuntos de ropa y vasquiña para mujer, conjuntos de ropa, calzón y ferreruelo para hombre, ferreruelos, faldellines franceses, gabanes, garnachas, galerillas, habitillos, hábitos, escapularios, jubones, manteos, mantos, mogiles, ropas de clérigo, reboziños, ropas de grana de la ciudad de Valencia: una para el trompeta; una para el bedel de las escuelas; una para los maceros, sayas infantiles, sayos castellanos, sotanillas, sotanas, tunicelas, tudesquillos y vasquiñas.

\section{El Tratado de Martín de Andújar}

El libro Geometría y trazas es una obra de Martín de Andújar impresa en la Imprenta Real el año 1640. Junto a la de Freyle, es mencionada por Campomanes en su Apéndice a la educación popular del siglo XVIII ${ }^{33}$. Dedicada a San Antonio de Padua, se divide en cinco partes. La

\footnotetext{
${ }^{31}$ Francisco de la Rocha, Carta de examen de la villa de Madrid, sin numerar.

${ }^{32}$ Francisco de la Rocha, Declaración de la vara de medir, fol. 2.

${ }^{33}$ Campomanes citado por Julián Marías, op. cit., p. 81.
} 
primera incluye el privilegio que le permite la venta del libro durante diez años, una nota que indica que cada pliego se tasa a cuatro maravedíes y la aprobación real tras la revisión del texto por Sebastián Gutiérrez, Maestro sastre examinador. En la segunda parte incorpora una historia eclesiástica a fin de demostrar la Antigüedad de la santa Verónica de Jaén. En la tercera parte presenta un tratado acerca de la reducción del paño, al igual que sastres anteriores habían hecho. En la cuarta parte declara las mismas características que acerca de la vara de medir habían expuesto sus colegas. En la quinta, adosa un índice de las trescientas veinte trazas ordenadas en distintos apartados: $1 .^{\circ}$, trazas sueltas de capas y ropillas de letrado y caballero; $2 .^{\circ}$, conjuntos masculinos franceses o españoles compuestos por calzones, ropillas y ferreruelos, sotanillas; $3 .^{\circ}$, vestidos de mujer (conjuntos de basquiñas y jubones con rebociños de labradoras; ropas, vaqueros); $4 .^{\circ}$, hábitos religiosos masculinos y femeninos para carmelitas, gerónimos, franciscanos, dominicos, monjas recoletas; $5 .^{\circ}$, hábitos de caballeros para justas reales; $6 .^{\circ}$, diferentes trazas (mantos de mujer simple, capa de pontifical, banderas, sayas, mongiles trenzados, una loba, una muceta de obispo, tres ropas rozagantes para saraos, española, francesa y lombarda) ${ }^{34}$.

\section{LOS TRATADOS DEL SIGLO XVIII}

De la España de la década de los veinte del siglo xviII hemos localizado un solo tratado de sastrería, el que escribiera Juan de Albayceta, que se publica en Zaragoza siguiendo el modelo de exposición de los patrones iniciado en el Renacimiento. Veámoslo a continuación:

\section{El Tratado de Juan de Albayceta}

El libro Geometría y trazas es compuesto por Juan de Albayceta, natural de la villa de Magallón (Zaragoza) e impreso por Francisco Revilla en Zaragoza el año 1720. El libro se divide en cinco partes. En la primera parte el autor incluye una tabla de todas las trazas ordenadas alfabéticamente. La segunda es el prólogo al lector en el que explica la necesidad por parte de los sastres de conocer las reglas y preceptos de la geometría y aritmética aplicados a la vara de medir para poder trazar cualquier género de ropa, algo que ya habían señalado sus homólogos Francisco de la Rocha, Martín de Andújar o un tal Francisco Cornago (del que sólo sabemos que es el autor de un famoso libro sobre el concepto de lo moderno que circulaba en esos momentos en España) ${ }^{35}$.

En la tercera parte el autor teoriza acerca de la vara de medir. Tras explicar el origen de la vara formada de la mano del hombre, define los números quebrados a los que anteriormente había aludido vagamente Juan de Alcega. Define número quebrado como el número correspondiente a cada una de las tres partes en las que divide la vara de medir, conocido por tercia. Junto a las tercias, hay fesmas (la sexta parte de la vara) y dozavos (la doceava parte de la vara). Reducida en dedos toda la vara, hace un total de cuarenta y ocho. Respecto a los caracteres y figuras con que J. de Albayceta identifica cada traza, éstos son exactamente los mismos que usaran Juan de Alcega y F. de la Rocha ${ }^{36}$. En la cuarta parte, J. de Albayceta advierte que se

\footnotetext{
${ }^{34}$ B.N., Anduxar, Martín, Geometría y tracas del Oficio de sastre, Madrid, Imprenta Real, 1640, fol. n. $^{\circ} 18$, Sala Cer- $^{-}$ vantes, sig. R 2493.

${ }^{35}$ Geografía e Historia, Universidad Complutense de Madrid. Albayceta, Juan, Geometría y trazas, Zaragoza, impreso por Francisco Revilla en 1720 , prólogo al lector, sin paginar.

${ }^{36}$ Albayceta, Juan, declaración de la vara de medir, ops. cit., fol. ssss.
} 

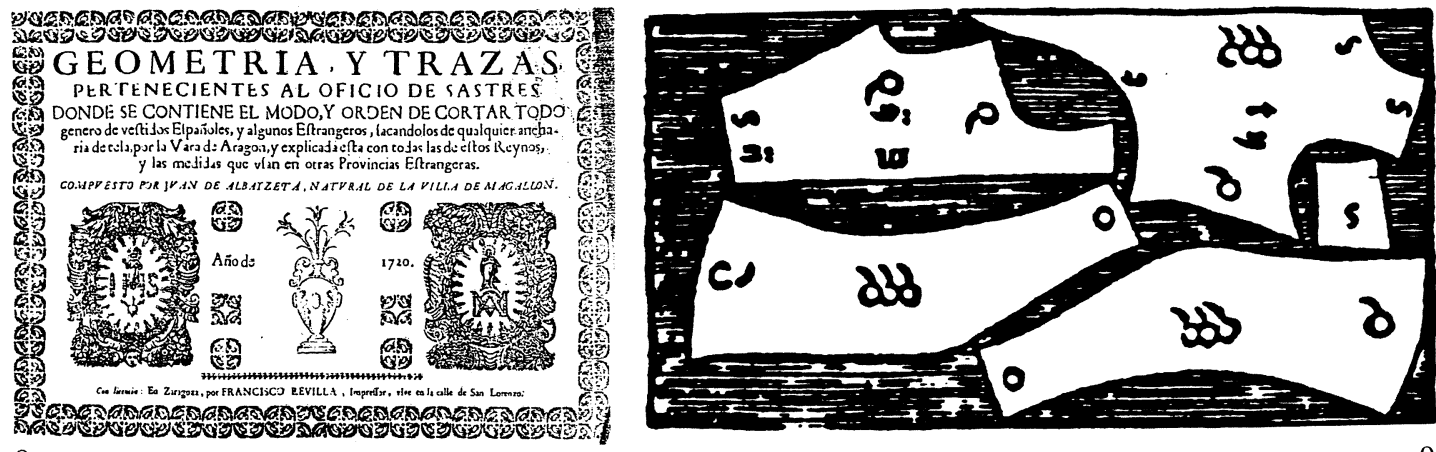

\section{I.tbon de Teda para muger.(ij.m).st)}

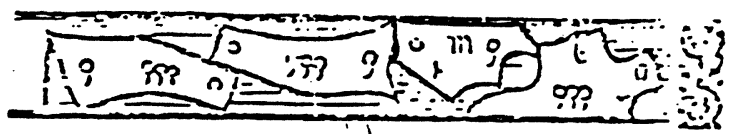

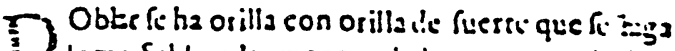
loraabaldran las unangas de la mano s zquicia y d cussfo denuellea nano derecha cunso cha tigteso, Ensra ü iedacios vasas y mediz, lo que qua ja es m.criler

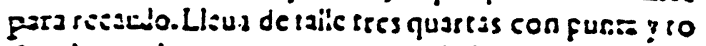
do y largo, de manga tres quastas. Es buena tracl

10
Iubon de tafecan de muger bboiii

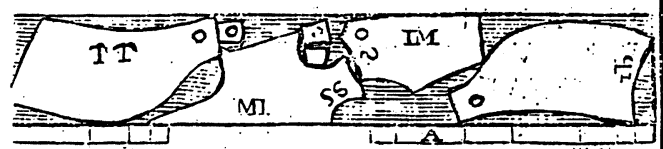

Para cortar efte otro jubón.de feda, es menefter doblar la feda a lo angofto, y de la parte de nueftra mano yzquierda fale la vna manga, y debaxo de la manga falen los quartos delanteros, traferos, y. la otra manga, y de los medios fale cuello, y.trecaudos para el dicho jubon. Lleua de feda por bara de Caitilla dos baras ochauo y tres dedos: y de bara Valenciana dos baras:y de Aragon dos baras quarca y dos $d$. dos : y de cana de Cataluña la metad menos de las buras de Aragon. Y Faldra de qualquiera de dichas por efta traça.

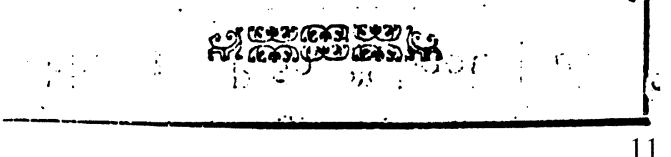

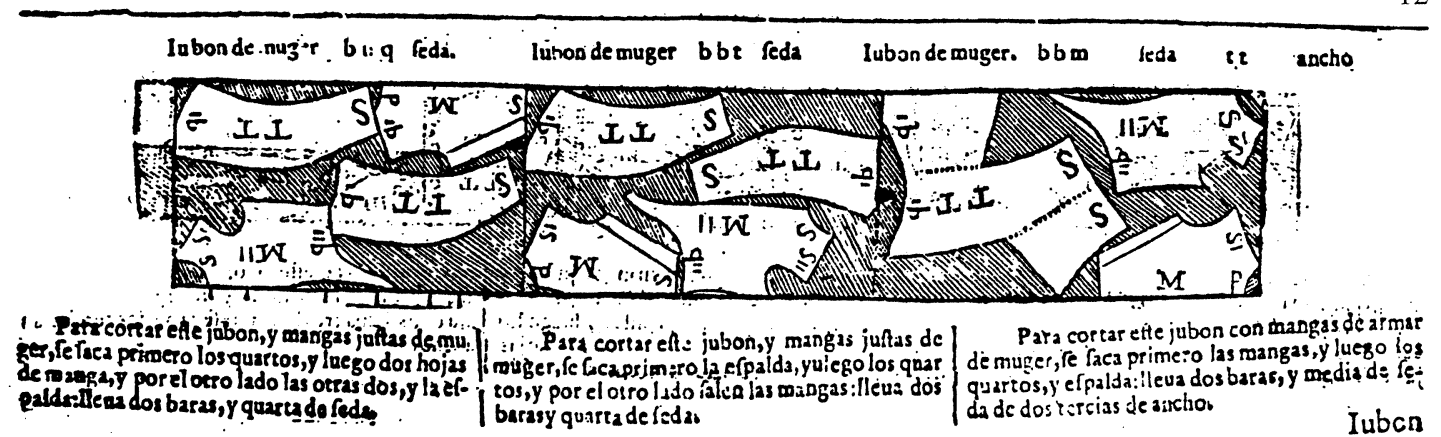

Fig. 8. Portada del tratado de sastrería Geometria y trazas efectuado por Juan de Albayceta, publicado por Francisco Revilla en Sevilla: 1640.

Fig. 9. Disposición de un patrón de jubón femenino por Juan de Alcega.

Fig. 10. Disposición de un patrón de jubón de mujer por Diego de Freyle siguiendo la metodología iniciada por Juan de Alcega.

Fig. 11. Disposición de un patrón de jubón de mujer por Francisco de la Rocha similar a Freyle y Alcega.

Fig. 12. Disposición de un patrón de jubón femenino por Martín de Andújar al modo de sus antecesores: Alcega, Freyle y Rocha. 
ha regido por la vara de Arasgón y ofrece una tabla con las equivalencias de las varas de otros Reinos de la Península Ibérica. Finalmente representa las trazas siguientes: bandera del reino de Aragón y bandera de guerra, basquiñas, capas de coro, capirotes, caparazones, chupas, casacas, dalmáticas, estandartes, garnachas, gramayas, gremiales, hábitos, jubones, manteos, ropas, ropillas, paños, pieles, sotanas, túnicas y ternos.

\section{CONOCIMIENTOS CIENTÍFICOS EN EL PROCESO DE ELABORACIÓN DEL TRAJE EN LA EDAD MODERNA}

El doble interrogante de porqué todos los tratados de sastrería españoles se imprimen casi simultáneamente con el mismo título: Geometría y trazas no deja de preocuparnos. La respuesta más sensata debemos encontrarla en el cambio de mentalidad que la época impone en sentido de que ya no se trata de guardar los secretos técnicos tan celosamente como en la Edad Media, se quiere incorporar lo experimental al mundo científico y artístico y se siente la necesidad de codificar los saberes existentes en la Edad Media en provecho de la mejora en la calidad de la enseñanza y aprendizaje de quienes pretendían llegar a ser Maestros de sastre.

Nuevos avances en el terreno de la geometría. Sí, pero ¿qué conocimientos científicos necesita un Maestro de sastre de la Edad Moderna para elaborar un tratado de sastrería? ¿Qué conocimientos científicos necesita un sastre cualquiera para cortar trajes? Cotejando los tratados de sastrería de los siglos XVI y XVII con los de geometría propiamente dicha de la misma época, las respuestas parecen sencillas. En los tratados de geometría, como el de Pérez de Moya, Tratado de Geometría especulativa y práctica (Imprenta de Juan Gracián. Alcalá, 1573), observamos que el autor explica el modo de dibujar las figuras paso a paso, indicando cómo ir trazando una línea tras otra y señalando sus respectivas medidas. Para inventar un método de corte, es obvio que los sastres desde la Edad Media hasta el siglo xviII no necesitan saber deducir las formas geométricas matemáticamente, aunque desde el siglo Xvi en que se pone de moda el estudio de la geometría, probablemente tendrían conocimientos elementales de dicha ciencia, de la que adoptarían el método de proyección de líneas, indicándonos las medidas más importantes en varas (un sexto de vara, un tercio de vara, etc.). Lo que los sastres no detallan con palabras son los pasos a seguir para realizar un patrón, es decir, por donde se empieza a tirar las líneas y cómo se suceden unas a otras, diferenciándose de un geómetra. Por su parte, los sastres no inventores de un método de corte no debían tener conocimientos de geometría. Simplemente sabrían adaptar las medidas del cliente al patrón de los tratados en los que se iban a basar. Luego, con el apoyo de una serie de herramientas, como la vara de medición lineal de hierro y el compás, los sastres podrían dibujar sobre la tela de manera exacta y concienzuda una serie de piezas, formando curvas para la sisa, el escote, el tiro de pantalón, trazando esquinas cuadradas y ángulos exactos. Naturalmente, el hecho de no representar la prenda a ojo, sino usando estos instrumentos, y el describir algunas figuras que por su forma son geométricas, significa un gran avance. Las figuras que más se utilizan son el círculo en todas sus variedades: medio círculo, un cuarto, una sección, el trapecio, el cono.

Hasta aquí la geometría. A continuación debemos explicar los conceptos tan a menudo confusos en la época sobre la traza y el diseño. Respecto al término traza, en el mundo del arte sartorial de la España Moderna por traza entendemos dibujo en dos modalidades: $1 .^{\circ}$, dibujo del patrón con las distintas piezas sin unir dispuestas sobre el tejido separadamente y desprovistas de toda decoración (adornos, encajes, puntillas, bordados, etc.), al modo que vemos hoy los patrones en los ordenadores de las empresas de confección industrial. Así aparecen los patrones de los tratados de los sastres del siglo XVI, XVII y XVIII; 2..$^{\circ}$ dibujo del patrón con las 
piezas unidas - aunque esto ocurre excepcionalmente-, que podemos comprobar en la dalmática del libro del sastre anónimo milanés y en las banderas y tiendas de campaña de los tratados de los siglos XVI (Alcega, Freyle) y xvII (Segovia, Andújar, Rocha). Incluso cuando Juan de Alcega explica cómo realizar una bandera de tafetán utiliza la palabra dibujarán: debuxaran encima qualquier obra que quifieren (fol. 76). En el siglo XvIII J. de Albayceta nos da los componentes de los patrones unidos de algunas dalmáticas y capas más complicadas, pero por regla general presenta los dibujos de los patrones con las piezas desunidas. Desde la aparición del tratado enciclopédico de Diderot publicado a finales del siglo xviII y, sobre todo en el siglo $\mathrm{xx}$, el concepto de diseño de un traje se complica, ya que el diseñador ha de presentar con claridad el traje tal y como se vería de frente, perfil y espalda con la debida indicación del tejido que se va a usar, sus estampados y bordados.

Por lo tocante al término diseño, en los tratados de sastrería de la España Moderna la palabra diseño no figura en ningún momento, pero en el mundo del arte, al aparecer, se usaron simultáneamente las voces de traza y diseño. Y es que la cultura de la traza y del diseño se ha pensado que posiblemente fueran diferentes en sus orígenes hasta que llegó un momento en que la cultura del diseño se superpuso a la de la traza o la absorbió ${ }^{37}$. Cuándo y dónde sucedió esto es más difícil de determinar. El concepto de diseño en Italia puede estar relacionado con el uso de la perspectiva y de la geometría. Un ejemplo de ello lo vemos en el Primo libro d'architettura de Serlio, publicado en París el año 1545 por la imprenta Iehan Martin. Al explicar Serlio cómo dibujar un edificio en perspectiva cónica y, basándose en la frase de que una imagen vale más que mil palabras, el artista usa el término diseño. Véase:

«No ti admirare, lettore, fi Lo scrivo molto fopra una cofa talhor, percio che, come da principio lo difsi, quefta e un arte che meglio se infegna conferendo prefentialmente, che in fcritto, $e$ in diffegno» ${ }^{38}$.

En España, en el Tratado de Diego de Sagredo Las Medidas del Romano (Ramón de Petras. Toledo: 1526. Facsímile, de. Albatros: 1976), primer compendio vitrubiano escrito en lengua vulgar, el pintor León Picardo decía a su interlocutor Tampeso (el propio Sagredo) que siempre que lo veía lo encontraba dibujando o traçando (¿haciendo bocetos?), con lo que da a entender que estas dos prácticas son distintas. Dos décadas después, en 1548, Francisco de Holanda, en De la pintura antigua, señala que el arquitecto, para saber el orden de edificación necesita saber dar las trazas e invenciones de los nobles edificios a los canteros, con lo cual, quizá, quiere decir que se debe saber dibujar ${ }^{39}$. En el siglo xvir la conexión teminológica aún persiste. Ensu libro Diálogos de la pintura, Carducho intenta aclarar los conceptos de traza y diseño. Para él traza es el alzado o montea, que es aquello que se delinea y se levanta sobre la superficie de la tierra. En cuanto al diseño, lo divide en interno y externo. Por diseño interno Carducho, como el italiano Zuccaro, entiende lo que se forma en el entendimiento, esto es, una forma o idea, orden regla, algo no material. Diseño externo es el que se ve circunscrito de for$\mathrm{ma}^{40}$. Acaso en arquitectura la idea de traza como montea o dibujo no quede clara, pues cuando, en el siglo xvir, el obrer de vila Cristofol Olivero fue a examinarse de su oficio para graduarse en la maestría, los examinadores le pidieron que trazase (¿dibujase o realizase?) una escala castellana (una vara). Cumplidas las peticiones, los examinadores le hicieron numerosas preguntas ${ }^{41}$.

${ }^{37}$ Cabezas, Lino, «Trazas y dibujos en el pensamiento gráfico del siglo xvı en España», Revista D'Art, núm. 17/18, 1992, pp. 226, 234; Diccionario de la Lengua, op. cit., p. 1293.

${ }^{38}$ U.L.V. Serlio, Primo libro d'architettura, París: Imprenta Iehan Martin, 1545, fol. 36 v ${ }^{\circ}$. Sig. Z-10/59.

${ }^{39}$ U.L.V. Holanda, Francisco de, De la pintura antigua (versión castellana de Manuel Denis, Madrid: 1563), p. 43.

${ }^{40}$ U.L.V. Carducho, De la pintura antigua (Madrid: Imprenta Real, 1865), p. 307, 514.

${ }^{41}$ A.R.V. José Alama, n. ${ }^{\circ}$ 6, año 1699, fol. 351. 


\section{PROCESO DE ELABORACIÓN DEL TRAJE EN LA EDAD MODERNA}

\section{Fase de la toma de medidas al cliente}

El sistema de patronaje industrial actual utiliza un método de corte estandarizado y a escala, en tanto que los sastres actuales se basan en un método manual cuyas medidas varían según el cliente. Siguiendo el método manual del sastre valenciano Andrés Espert, uno de los que gozan de mayor predicamento en esta ciudad en la actualidad, con una cinta métrica y regla, el sastre o la modista debe tomar las siguientes medidas al cliente: verticales (nunca a tierra por detrás, largo de manga, largo de talle, largo de falda y caída de pecho) y perimetrales (cuello, pecho, sobrepecho, separación de pechos, cintura y cadera). El modo de tomar las medidas verticales comienza con la de la nuca, que se saca con ayuda de una regla de 1 metro o 1'20 metros, la cual se apoya completamente vertical sobre la espalda del cliente. El largo de manga se toma desde la nuca, pasando sobre el hombro y por delante del brazo hasta la mitad del metacarpo del dedo pulgar. El largo de talle va desde la nuca hasta la parte más hundida de la cintura en la espalda. El largo de falda va desde la cintura sobre el costado hasta donde se desee. La caída del pecho se adquiere desde la nuca por encima del hombro y clavícula hasta la punta más saliente del seno. Respecto a las medias perimetrales, la medida del cuello se toma justo sobre la piel, por la parte más delgada, y se le añaden dos centímetros para las prendas que van sobre la piel y cuatro centímetros para las que van sobre aquéllas. La medida del pecho se toma de delante hacia atrás, pasando sobre el tórax y controlando la parte más saliente de los omóplatos. La medida del sobrepecho se toma como la medida del pecho, pero controlando la parte más saliente de los senos. La separación del pecho es la distancia de la punta de los senos. La cintura se toma justo alrededor del talle. La cadera se toma controlando la parte más saliente de los glúteos y por delante del vientre, procurando que la cinta métrica esté paralela al suelo. Frente a la época actual, en los libros de corte de sastrería de la Edad Moderna no se especifica el modo de tomar las medidas. Sin embargo, en ellos se dan las medidas del largo y ancho del traje tanto del delantero como de la espalda, siendo éstas unas más que suficientes medidas para que, al decir de la diseñadora Mariló Mascuñán, el sastre pueda elaborar su patrón, acoplándose las demás medidas después.

\section{Fase de pasar las medidas al tejido}

Pasan los Maestros de sastre o alfayate ${ }^{42}$ y diseñadores experimentados actuales las medidas del cliente al tejido directamente, sin usar los denominados moldes (en palabras de la época) o plantillas, modelos en cartón que servían de guía para cortar el patrón también a los Maestros constructores en la Edad Media para que los albañiles las utilizasen. Los sastres en la Edad Moderna trabajarían de dos modos, bien sin usar plantillas bien utilizándolas. Pensemos que van a elaborar una plantilla. Para ello, al decir de Mariló Mascuñán, lo primero que deben hacer es coger un cartón, después determinar el orden de dibujo de las prendas, que coincidirá o no con el posterior orden de cortado, es decir, ver si van a dibujar primero el delantero o la espalda, si van a comenzar por una orilla o por el cuello. Luego determinarán la

\footnotetext{
${ }^{42}$ Alfayate (m.s.). Artesano dedicado al corte y confección de indumentaria masculina y femenina. Usado principalmente en Castilla, el término equivale a sastre. Etimológicamente procede, según Covarrubias, del verbo árabe hayete que significa coser (...) y dice ser nombre superlativo del mefmo verbo, para dar a entender que, aunque todos faben cofer fi alguna cosa fe les rompe, este alfayate lo tiene por oficio. Véase: Covarrubias, Tesoro de la Lengua Española, Imprenta de la Casa Real, 1611, p. 43.
} 


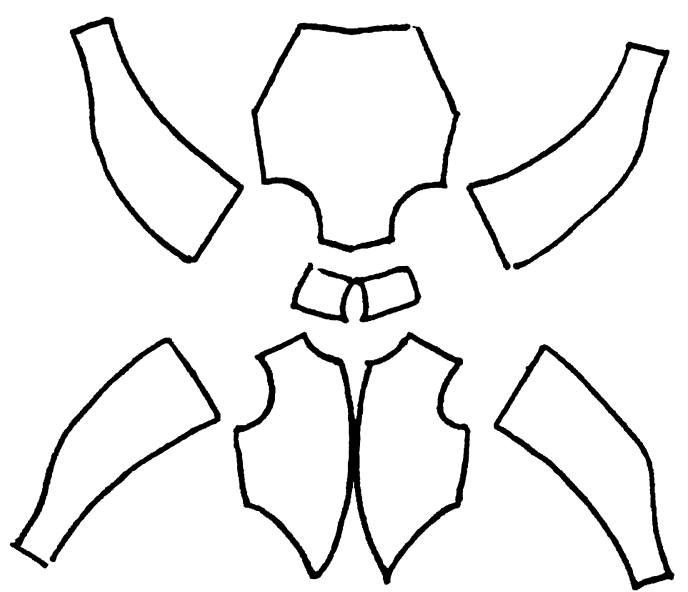

13
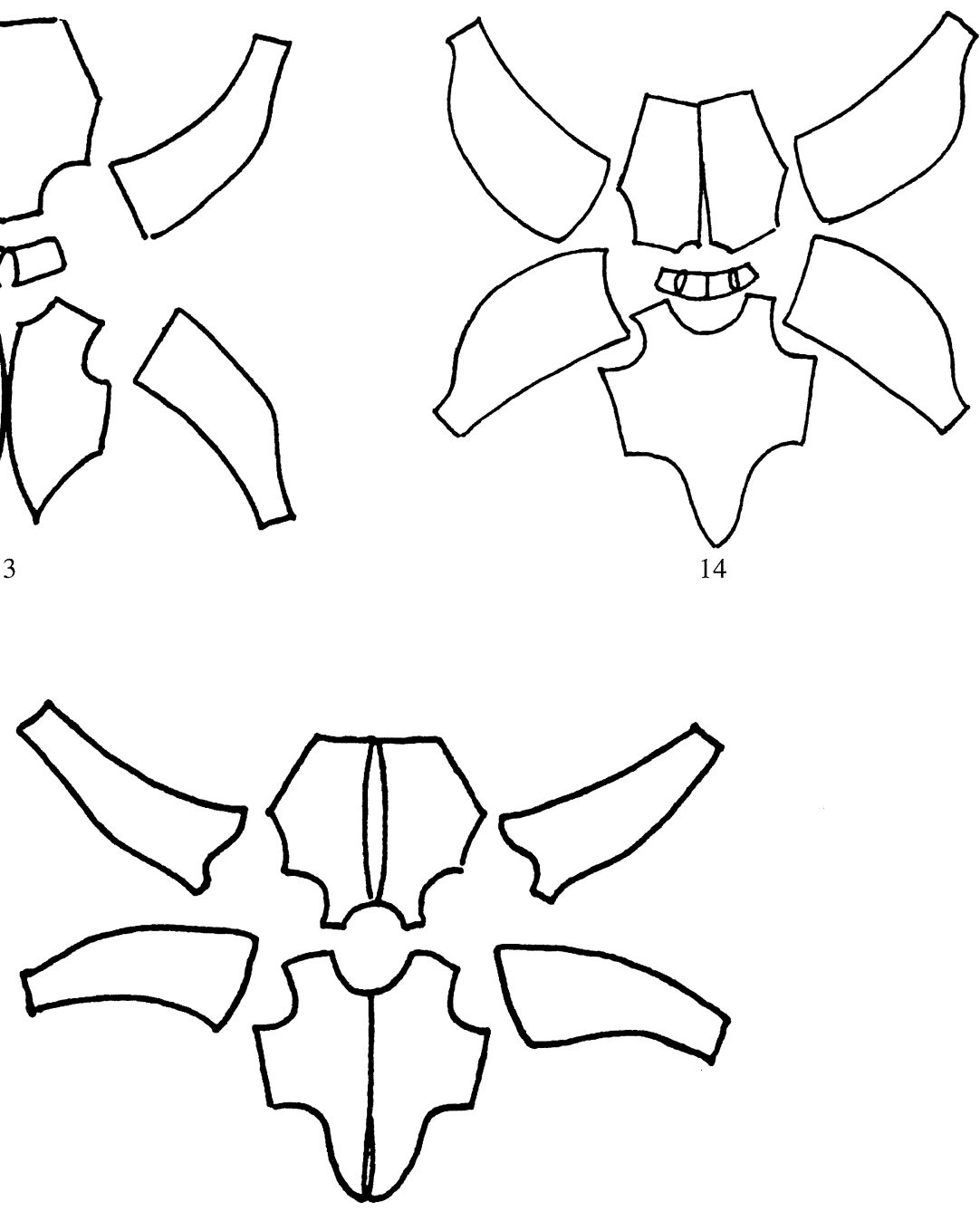

15
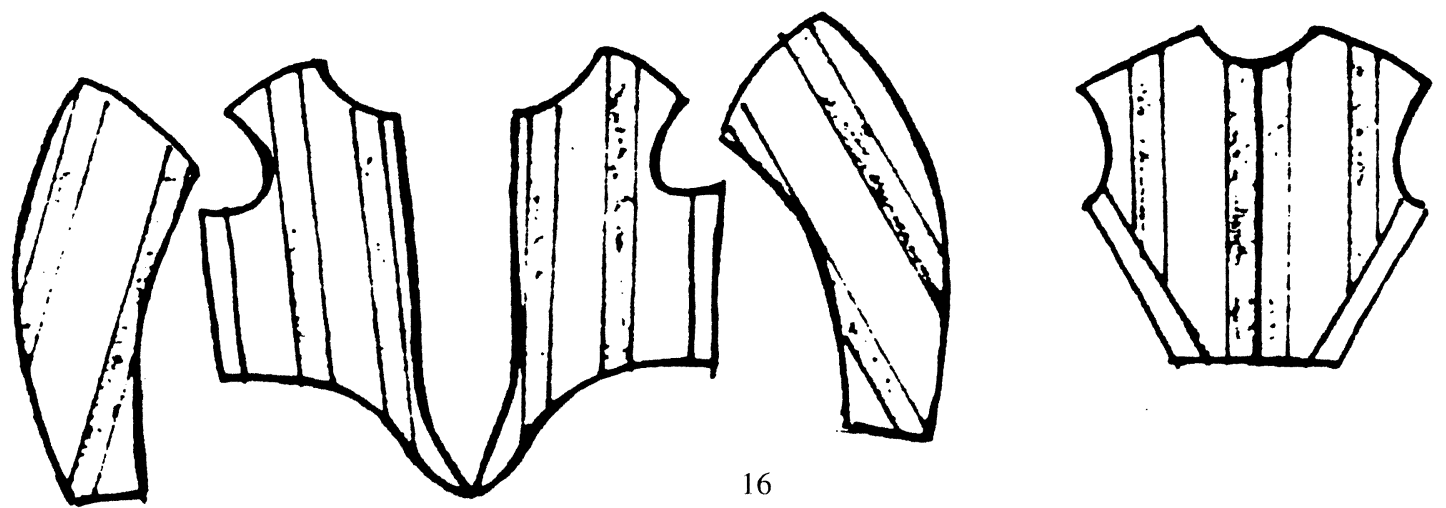

Fig. 13. Interpretación del patrón de jubón de mujer de Juan de Alcega realizado por la diseñadora Mariló Mascuñán. Fig. 14. Interpretación del patrón del jubón de mujer de Francisco de la Rocha por Mariló Mascuñán.

Fig. 15. Interpretación del patrón de mujer de Diego de Freile por Mariló Mascuñán.

Fig. 16. Interpretación del patrón del jubón de mujer de Martín de Andújar por Mariló Mascuñán. 
dirección del patrón para colocarlo sobre el tejido, etc. En la Edad Moderna se concede gran importancia a la dirección del hilo, llamado pelo del tejido, así como a la dirección del brocado, bordado o estampado de la tela; por eso lo especifican con harto detalle. En realidad, el modo de colocación de las plantillas sobre la tela presenta tres modalidades: al hilo, al través o al bies. El primero y más frecuente es cuando la pieza guarda el sentido del hilo, que suele ser el largo de la tela, si bien en determinadas ocasiones se encuentra de las otras dos maneras. $\mathrm{Al}$ través, es cuando el patrón va colocado a lo ancho de la tela. Juan de Alcega corta, en el conjunto que denomina bestido, la espalda de la ropilla al través (el delantero al hilo) y una pierna de los calzones (la otra al hilo). Asimismo, en el inventario de los bienes del Marqués de Covega, hermano del Barón de Cheste, realizado en Valencia el 29 de junio de $1709^{43}$, encontramos una casaca de felpa negra al traves, de galo de or ya usades. Al bies es cuando el patrón se coloca en la parte diagonal de la tela, otorgando a la prenda una mejor caída. El hecho de encontrar cortadas al bies las faldillas de la ropilla del anteriormente mencionado bestido en el . tratado de sastrería de Juan de Albayceta, desmiente la hasta ahora extendida teoría de que este tipo de corte fue inventado por Madelaine Vionet a principios del siglo xx. No obstante, entendemos que esta modista generalizó su uso.

Puesto el patrón al bies, al hilo o al través, el modo en que los sastres realizan la plantilla es un proceso que nos recuerda a la tediosa manera que tiene una araña cuando elabora su tela para capturar a las presas. Ambos van uniendo una línea a otra con objeto de que el tejido resultante quede bien trabado. Los sastres seleccionan Primero un centro que será el punto de apoyo o de partida denominado árbol, a partir del cual van a ir tirando o marcando las restantes líneas con un jaboncillo, que suele ser blanco o rojo para que resalte sobre la tela, y de fácil borrado en caso de equivocación. Para esta acción los sastres usan la expresión pasar o dar un xabón. Después, pongamos por caso que van a realizar una prenda trapezoidal como la saya, primero marcan el largo total, desde ella y con ayuda de una vara sacarían las medias del ancho del cuello, talle, cintura, cadera y escote. Luego obtendrían las demás medidas como la sisa con ayuda de un compás. Normalmente las medidas que se marcan son la mitad de las medidas enteras porque la tela va doblada mostrando su lomo (hoy, se usa esta palabra para indicar la parte por donde doblan a lo largo de las piezas las pieles, tejidos y otras $\operatorname{cosas}^{44}$ ) o cortada por piezas, de suerte que éstas queden idénticas. Generalmente, la prenda es demasiado ancha o larga y no cabe en el ancho del tejido, lo que suelen remediar los sastres dibujando la parte que no cabe al lado de la prenda e indicándola claramente con pequeños puntitos. A esas piezas las llaman cuchillos o nesgas (hoy se definen como tiras o piezas de lienzo o paño que, cortadas describiendo una forma triangular, se añadían o entretejían a las ropas con el objeto de darles vuelo o el ancho que necesitaban ${ }^{45}$ ). Realizada la plantilla, los sastres que quieran basarse en ella sólo tienen que colocarla sobre el tejido, dibujar los bordes e ir corrigiendo las medidas standard hasta hacerlas coincidir con las medidas reales de los clientes.

A continuación, los Maestros de sastrería cortan la prenda, la hilvanan y prueban al cliente, entonces la galantean usando palabras de Albayceta en el siglo xviII, afinan o pulen según el vocabulario moderno empleado por Maestros de sastrería contemporáneos, como el anterior presidente del Gremio de sastres D. Víctor Seligra y su antecesor D. José Mas. En otras palabras, van modificando lo que hay de modificable en la prenda, pequeñas zonas para enriquecerla o señalar bordados o pasamanería. Modificada la prenda, los Maestros pasan al velador, estancia donde trabajan los oficiales para que éstos la cosan o acofturen, en palabras de Juan de Albayceta. Ya cosida, en caso de necesitar bordados, entregan la prenda a los bordadores.

\footnotetext{
43 A.P.P.V. Joan Baptista Blasco, n. ${ }^{\circ}$ 05020, fol. 102.

${ }^{44}$ Diccionario de la Lengua Española, op. cit., p. 813

${ }_{45}$ Diccionario de la Lengua Española, op. cit., p. 917.
} 
Hasta ahora hemos visto la manera de pasar las medidas al tejido. Otro aspecto no menos interesante es el de saber cómo se colocan los patrones dentro de los libros de sastrería españoles, lo cual ha sido aclarado por el historiador alemán Ingeborg Petrascheck-Heim ${ }^{46}$, quien señala dos modos de proceder diferentes en España y Alemania. En España, Alcega y Andújar utilizan el mismo sistema de patronaje consistente en dibujar primero el patrón para después pegarlo dentro del libro - aplicando el mismo patrón a los distintos tejidos que vayan a utilizar- y, dependiendo del tamaño necesitado, es decir, de la talla del cliente, van reduciendo o ampliando estos patrones. Frente a este método, los sastres alemanes de la ciudad de Enns incluyen dentro del libro los patrones con distintas medidas y, por tanto, resulta más cómodo, fácil de identificar y económico. Es posible que estos libros sean los precedentes del que probablemente sea el primer libro de sastrería impreso con medidas standar, creado en Inglaterra en 1829 por John Jackson.

\section{LA SASTRERÍA: ¿UN ARTE MECÁNICO O LIBERAL?}

El arte y la moda, no obstante ser disciplinas diversas, asumen los ecos del debate histórico que trata de definir las artes liberales y las mecánicas. En las primeras etapas de la Edad Moderna se trata de incrementar el valor del arte pictórico y arquitectónico debido a que utiliza geometría y perspectiva. De hecho, en el siglo xvi Francisco de Holanda, en De la pintura antigua, habla de la nobleza de la pintura y de esa suerte proceden en el siglo siguiente Carducho en Diálogos de la pintura y Pacheco en Arte de la Pintura. En sastrería, notables poetas como Alarcón, en el siglo XVI, tratan de elevar al sastre Diego de Freyle a la categoría de artistas (no especifica artistas liberales) porque aplica la geometría a la sastrería, diferenciándolo de los meros artesanos. En el siglo xviII se avanzará un paso más cuando la filosofía ilustrada, con Campomanes a la cabeza, trate de profesionalizar, elevando su categoría cultural, las artes mecánicas (sastrería, relojería, zapatería, carpintería, etc.). Además, bibliógrafos como Nicolás Antonio (siglo XVIII), Pérez Pastor (siglo XVIII), Bartolomé Gallardo (siglo XIX) y Francisco Vindel (siglo xx) realzan la labor intelectual de los sastres Juan de Alcega, Francisco de la Rocha y Martín de Andújar por haber inventado un método de corte. Con todo, todavía éstos consideran la sastrería un arte mecánico, ya que cuando Nicolás Antonio define a F. de la Rocha lo denomina operario mecánico geométrico: infcriptus auctor legitus operis mechanicogeometrici huytis. El resto de los bibliófilos no aplica a los sastres ningún calificativo concreto. Hoy, en el otoño de siglo xx, se pretende abolir desde las instituciones de Arte la pretérita división de las artes. Teóricamente ya no hay artes liberales o mayores y mecánicas o menores, sino que hay un Arte que engloba a cualquier profesión siempre que los artistas den muestra de su talento creador. La prueba más rotunda la tenemos en la nominación el año 1998 de Jesús del Pozo como miembro de la Academia de San Fernando, mérito hasta ahora reservado a grandes intelectuales. Sin embargo, en la práctica, aún hoy, los diseñadores de moda se cuestionan si un traje puede considerarse una obra de arte o si la moda es Arte o un tipo particular de Arte, y las opiniones son un tanto diversas ${ }^{47}$.

\footnotetext{
${ }^{46}$ Véase el libro de Ingeborg Petrascheck-Heim Figurinen nach alten Schnitt büchem. Katalog zur Ausstellung des stadmuseum. Linz, 1968, p. 17.

${ }^{47}$ Preguntados sobre esta cuestión los diseñadores que presentaron sus trajes inspirados en cuadros del Museo de Bellas Artes de Valencia con motivo de la Exposición Arte y Moda, celebrada en dicho Museo en 1999, encontramos sutiles diferencias de opiniones. Opina que la moda no es un arte M. ${ }^{a}$ José Navarro (la moda adapta la imaginación a la industria mientras el Arte recrea la imaginación). Duda si un vestido es una obra de arte o no Juan Andrés Mompó; que la moda es un arte menor lo piensa Enrique Lodares (no es igual pintar un cuadro que hacer un vestido); que la moda es un Arte o más bien un vínculo del Arte lo defiende Francis Montesinos.
} 


\section{CONCLUSIÓN}

Los tratados de sastrería vienen a poner de relieve el predicamento e importancia de los métodos de representación gráfica en la enseñanza y aprendizaje de la sastrería en la España Moderna, constituyendo documentos de capital importancia para el conocimiento del proceso de fabricación en la Edad Moderna, lo mismo que ocurriera en otros campos, como la geometría, las artes plásticas, la arquitectura, la relojería, la navegación, la astronomía, etc. Además, estos tratados encierran un caudal de conocimientos operativos y asequibles en la actualidad para los estudiosos de la sastrería, historiadores del arte o diseñadores de moda. Por otro lado, la iniciativa de los sastres de la Edad Moderna hace evolucionar la moda por medio de la técnica del oficio, creando modelos similares con pequeñas variaciones, según las interpretaciones de los patrones realizadas por Mariló Mascuñan. Por ejemplo, en el siglo Xvi Alcega presenta variaciones de jubones masculinos con un corte bien en el delantero bien en la espalda. Después, Freyle crea un modelo de jubón masculino con un corte tanto en el delantero como en la espalda para que acople mejor. Alcega presenta una capa de hombre circular llamada bohemio con dos cortes horizontales, a la que Freyle le añade tes cortes más dispuestos en sentido oblicuo, otorgando a la capa más vuelo. En el siglo XVII Rocha da varios modelos de jubones femeninos, uno de ellos presenta un corte en la espalda y el otro modelo tiene dos cortes ubicados en la espalda y en el delantero. Andújar ofrece un jubón de mujer con dos cortes en la espalda y en el delantero y, además, emplaza en las caderas unos cortes en sentido diagonal a fin de que el jubón acople mejor a la cintura. 